\title{
Rapid Direct Nucleic Acid Amplification Test Without RNA Extraction for SARS-CoV-2 Using a Portable PCR Thermocycler
}

\author{
Soon Keong Wee ${ }^{\circledR}$, Suppiah Paramalingam Sivalingam $@$ and Eric Peng Huat Yap * \\ Lee Kong Chian School of Medicine, Nanyang Technological University, Singapore 308232, Singapore; \\ wees0021@e.ntu.edu.sg (S.K.W.); spsuppiah@ntu.edu.sg (S.P.S.) \\ * Correspondence: ericyap@ntu.edu.sg
}

Received: 9 May 2020; Accepted: 16 June 2020; Published: 18 June 2020

\begin{abstract}
There is an ongoing worldwide coronavirus disease 2019 (Covid-19) pandemic caused by severe acute respiratory syndrome coronavirus 2 (SARS-CoV-2). At present, confirmatory diagnosis is by reverse transcription polymerase chain reaction (RT-PCR), typically taking several hours and requiring a molecular laboratory to perform. There is an urgent need for rapid, simplified, and cost-effective detection methods. We have developed and analytically validated a protocol for direct rapid extraction-free PCR (DIRECT-PCR) detection of SARS-CoV-2 without the need for nucleic acid purification. As few as six RNA copies per reaction of viral nucleocapsid $(\mathrm{N})$ gene from respiratory samples such as sputum and nasal exudate can be detected directly using our one-step inhibitor-resistant assay. The performance of this assay was validated on a commercially available portable PCR thermocycler. Viral lysis, reverse transcription, amplification, and detection are achieved in a single-tube homogeneous reaction within $36 \mathrm{~min}$. This minimizes hands-on time, reduces turnaround-time for sample-to-result, and obviates the need for RNA purification reagents. It could enable wider use of Covid-19 testing for diagnosis, screening, and research in countries and regions where laboratory capabilities are limiting.
\end{abstract}

Keywords: Point-of-care; Diagnostics; DIRECT-PCR; portable PCR; SARS-CoV-2; Covid-19

\section{Introduction}

A novel coronavirus disease 2019 (Covid-19) caused by severe acute respiratory syndrome coronavirus 2 (SARS-CoV-2) was reported in Wuhan, China in December 2019 [1]. The World Health Organization (WHO) has declared Covid-19 a pandemic, triggering various travel restrictions, border control, quarantine and social distancing measures in many countries [2]. Despite these interventions, the pandemic continues to spread globally, with its epicenter moving across continents [3], including in countries with well-developed public health systems and aggressive implementation of measures [4]. There is also a possibility of a second wave of cases with lifting of the lock-down measures. For instance, Singapore, which reported its first imported case on 23rd January 2020 and the first local transmission on 4th February 2020 [5,6], saw a ten-fold increase in cumulative cases over 21 days in early April [7].

The first SARS-CoV-2 genome was published and deposited in NCBI database as Wuhan-Hu-1, GenBank accession number MN908947 on 14 January 2020 [8]. This allowed several laboratories around the world, including our laboratory, to develop nucleic acid amplification tests (NAAT) to detect SARS-CoV-2 genetic materials [9]. Currently, there are many quantitative RT-PCR (RT-qPCR) based NAAT being developed for SARS-CoV-2 [10]. These target various viral genes including the nucleocapsid (N), polyprotein (ORF1ab), spike (S), and envelope (E) gene region of the positively stranded $29.9 \mathrm{~kb}$ RNA virus. These tests are widely used to screen suspected Covid-19 patients, 
returning travelers from outbreak areas, close contacts of cases, and healthy individuals who may be asymptomatic carriers of the virus [5,11]. Typically, two respiratory samples such as sputum or nasal, throat, and nasopharyngeal swabs collected consecutively over two days are tested to confirm a diagnosis or to confirm recovery [5]. Diagnostic testing is recognized as a rate-limiting step, and there is a global need to ramp up laboratory capacity, in both well developed and low income countries $[4,12]$. This is worsened by the possibility that asymptomatic individuals in the community could transmit infection, therefore increasing the need to screen healthy individuals or those with mild symptoms [13-15].

Quantitative RT-PCR is being deployed as the primary method for SARS-CoV-2 detection in research and hospital laboratories on account of its single-molecule sensitivity, ease of assay design, and availability of reagents. However, there are several technical challenges. These tests require RNA extraction, followed by amplification and detection. Current state-of-the-art PCR typically require $70 \mathrm{~min}$ for RNA extraction and a further $90 \mathrm{~min}$ for amplification $[15,16]$. Highly trained technical staff, costly equipment (costing USD 20K-50K), and facilities are required. These factors contribute to longer turnaround-time, costs of manpower, capital, and consumables, as well as risks of carryover contamination and biosafety risks when handling clinical samples. Currently there is a limited supply of extraction reagents and test kits worldwide $[16,17]$. In addition, asymptomatic individuals have also led to pre-symptomatic transmission in the community which further increases demand for laboratory testing [13]. These factors have motivated us to explore ways to simplify and shorten the protocols, without significant compromise to the high sensitivity and specificity of RT-qPCR. We therefore propose a novel method, which we termed direct rapid extraction-free PCR (DIRECT-PCR) for Covid-19 diagnosis.

PCR directly from crude samples without nucleic acid purification has been attempted before using inhibitor-resistant enzymes, modified buffers and additives in the mastermix. Our group [18] and others [19] have previously detected whole dengue virus in a single tube reaction containing serum and plasma in up to $8 \%(\mathrm{v} / \mathrm{v})$. Direct amplification from samples has also been reported for the detection of other RNA viruses, including African Chikungunya virus [20], noroviruses [21], and bovine viral diarrhea virus [22] and from a variety of matrices, including serum, throat swab and feces [23]. However, the presence of PCR inhibitors, such as mucin and proteins, poses a challenge for direct amplification from respiratory samples [24], and there are limited studies amplifying coronaviruses directly from such specimens. We have developed a DIRECT-PCR protocol using widely used and validated PCR primers, established its analytical performance with both DNA and RNA templates in respiratory samples, and transferred the protocols from benchtop to a portable thermocycler.

\section{Materials and Methods}

\subsection{Samples and Controls Used for Assay Development}

For biosafety purposes, synthetic nucleic acids rather than whole virus templates were used for the development of this assay. As SARS-CoV-2 is a positive stranded RNA coronavirus, we synthesized single-stranded RNA (ssRNA) of the amplicon sequence (99 bp) for SARS-CoV-2 nucleocapsid (N) gene (Integrated DNA Technologies, San Diego, CA, USA). Plasmid DNA containing the N gene of SARS-CoV-2, MERS-CoV, and SARS-CoV were also used as positive controls (2019-nCoV RUO Plasmid Controls, Integrated DNA Technologies, San Diego, CA, USA). ssRNA of human ribonuclease $\mathrm{P}(\mathrm{RP})$ gene amplicon sequence (65 bp) was synthesized for use as internal control (Integrated DNA Technologies, San Diego, CA, USA).

\subsection{Collection and Processing of Sputum and Nasal Exudate Samples}

Approximately $1 \mathrm{~mL}$ of SARS-CoV-2-negative sputum and nasal exudate from a healthy adult research team member was collected by hypersaline inhalation, and used for spike-in of ssRNA and plasmid controls. Briefly, the respiratory samples were mixed in 1:1 (v/v) ratio with Sputasol (Oxoid, 
Basingstoke, England) and vortexed for $5 \mathrm{~min}$ to remove the viscosity to allow direct addition to the PCR reaction mix.

\subsection{Primer and Probes}

All primers and probes targeting SARS-CoV-2 ORF1ab and N genes were previously published by the Chinese Center for Disease Control and Prevention, Beijing, China [25,26]. The human Ribonuclease $\mathrm{P}(\mathrm{RP})$ gene primer and probe were previously published by US Centers for Disease Control and Prevention (CDC) protocol and was added as an internal control to detect the presence of human RNA in the samples [27]. All oligonucleotides, primers, and probes were commercially purchased from Integrated DNA Technologies (Integrated DNA Technologies, San Diego, CA, USA).

\subsection{RT-qPCR and DIRECT-PCR}

Quantitative RT-PCR was initially performed in monoplex single-tube reaction mixture using two different separate mastermixes. For standard RT-qPCR, PCR master mix containing Invitrogen SuperScript $^{\mathrm{TM}}$ III Platinum ${ }^{\mathrm{TM}}$ One-Step RT-qPCR Kit (Life Technologies, Austin, TX, USA) mastermix, $400 \mathrm{nM}$ of forward and reverse primers, $200 \mathrm{nM}$ of FAM-based probe, and $16 \mathrm{U}$ of RNaseOUT ${ }^{\mathrm{TM}}$ Recombinant Ribonuclease Inhibitor (Life Technologies, Austin, TX, USA) was used. For DIRECT-PCR, it was performed using a PCR enhancer and inhibitor-resistant enzymes (Direct One-Step S/P RT-qPCR TaqProbe Kit, VitaNavi Technology LLC, Ballwin, MO, USA), supplemented with $400 \mathrm{nM}$ of forward and reverse primers, $200 \mathrm{nM}$ of FAM-based probe, and $16 \mathrm{U}$ of RNaseOUT ${ }^{\mathrm{TM}}$ Recombinant Ribonuclease Inhibitor (Life Technologies, Austin, TX, USA). Two microliters of ten-fold diluted RNA template in duplicates was added in a total volume of $20 \mu \mathrm{L}$. DNase/RNase-free water was used as the non-template control (NTC). All reactions were completed in a 96-well plate format (MicroAmp ${ }^{\mathrm{TM}}$ Fast Optical 96-Well Reaction Plate with Barcode, $0.1 \mathrm{~mL}$, Applied Biosystems, Beverly, MA, USA). The RT-qPCR assays were performed under the following conditions: reverse transcription at $50{ }^{\circ} \mathrm{C}$ for 15 min and initial denaturation at $95^{\circ} \mathrm{C}$ for $1 \mathrm{~min}, 45$ cycles of denaturation at $95^{\circ} \mathrm{C}$ for $10 \mathrm{~s}$ and annealing at $55^{\circ} \mathrm{C}$ for $45 \mathrm{~s}$ using a standard benchtop real-time thermocycler (StepOnePlus Real-Time PCR System, Applied Biosystems, Beverly, MA, USA). A specimen was considered positive if the amplification curve crossed the threshold line within 40 quantification cycle $\left(\mathrm{C}_{\mathrm{q}}<40\right)$.

\subsection{DIRECT-PCR of SARS-CoV-2 N Gene in Sputum and Nasal Exudate}

All samples used for the spike-in experiments were freshly prepared. Briefly, $8.5 \mu \mathrm{L}$ of sputum and nasal exudates sample mix with Sputasol were aliquoted. RNaseOUT ${ }^{\mathrm{TM}}$ Recombinant Ribonuclease Inhibitor $(0.5 \mu \mathrm{L}(20 \mathrm{U})$ ) (Life Technologies, Austin, TX, USA) was added to each aliquot and inverted to mix. Meantime, the RNA template was ten-fold serially diluted in DNase/RNase-free water to achieve 8 orders of magnitude. Next, $1 \mu \mathrm{L}$ of diluted RNA template was spiked into the sputum and nasal exudate mix forming a total volume of $10 \mu \mathrm{L}$. Subsequently, $2 \mu \mathrm{L}$ of RNA spiked-matrices containing $42.5 \%$ sputum and nasal exudate respectively were directly added into the $20 \mu \mathrm{L}$ reaction volume of inhibitor-resistant PCR reaction mix containing a PCR enhancer and inhibitor-resistant enzymes (Direct One-Step S/P RT-qPCR TaqProbe Kit, VitaNavi Technology LLC, Ballwin, MO, USA), forward and reverse primers, FAM-based probe, and RNaseOUT ${ }^{\mathrm{TM}}$ Recombinant Ribonuclease Inhibitor (Life Technologies, Austin, TX, USA) as described above. RNA template in DNase/RNase-free water was used as positive control. A sputum only and nasal exudate only sample containing Sputasol were also added as a blank non-template control (NTC) for the respective matrices. The reaction mixture was incubated at $50{ }^{\circ} \mathrm{C}$ for $15 \mathrm{~min}$, denatured at $95{ }^{\circ} \mathrm{C}$ for $1 \mathrm{~min}$, followed by 45 cycles of denaturation at $95{ }^{\circ} \mathrm{C}$ for $10 \mathrm{~s}$ and annealing at $55^{\circ} \mathrm{C}$ for $45 \mathrm{~s}$ on a standard benchtop real-time thermocycler (StepOnePlus Real-Time PCR System, Applied Biosystems, Beverly, MA, USA).

The lowest limit of detection (LoD) was determined using SARS-CoV-2 N RNA template that was ten-fold serially diluted in SARS-CoV-2-negative sputum and nasal exudate samples. LoD was defined as the last dilution in which quantification cycle $\left(C_{q}\right)$ value could be detected in all replicates. 
The linear range correlation between the theoretical log copy number calculated from the concentration molarity of synthetic nucleic acids and $C_{q}$ value was established applying a best-fit line to the data by linear regression analysis. PCR efficiency (E) was calculated from the slope of the linear equation.

\subsection{Optimization of Fast DIRECT-PCR Assay}

The DIRECT-PCR assay was modified in order to further reduce turnaround time and reagent cost. The final reaction volume was reduced from $20 \mu \mathrm{L}$ to $10 \mu \mathrm{L}$, while reducing the number of cycles from 45 to 40 , reducing reverse transcription (RT) step from $15 \mathrm{~min}$ to $5 \mathrm{~min}$, reducing initial denaturation from $1 \mathrm{~min}$ to $30 \mathrm{~s}$ and reducing annealing duration from $45 \mathrm{~s}$ to $15 \mathrm{~s}$. Ten-fold serially diluted RNA spike-in matrices described above were used in duplicates to evaluate the modified assay to determine a fast protocol for detection of SARS-CoV-2. Briefly, an aliquot of $1 \mu \mathrm{L}$ of template was added in the $10 \mu \mathrm{L}$ PCR reaction mix mentioned above. Similarly, the plasmid controls of N gene from SARS-CoV-2, MERS-CoV and SARS-CoV were ten-fold serially diluted in DNase/RNase-free water to achieve 6 orders of magnitude, respectively. Subsequently, $1 \mu \mathrm{L}$ of diluted plasmid template was spiked into the sputum and nasal exudate mix containing Sputasol and RNaseOUT forming a total volume of $10 \mu \mathrm{L}$ as described above. The internal control using human Ribonuclease P (RP) gene was evaluated by the DIRECT-PCR of human RP in the sputum and nasal exudate using the assay described. Serially diluted human RP RNA template in water was used as the positive control. MERS-Cov and SARS-Cov plasmid controls were added as negative controls. The amplification was performed on a standard benchtop real-time thermocycler (StepOnePlus Real-Time PCR System, Applied Biosystems, Beverly, MA, USA).

The detailed protocol of DIRECT-PCR for SARS-CoV-2 is available as Supplementary Information (Supplementary S1).

\subsection{Performance of Portable Real-Time Thermocycler}

DIRECT-PCR assays were validated on the portable thermocycler (MyGo Mini, IT-IS Life Science Ltd, Dublin, Ireland) using the same monoplex single-tube protocols described above. The portable thermocycler is lightweight at less than $2 \mathrm{~kg}$ with a dimension of $12 \mathrm{~cm}$ (width) by $12 \mathrm{~cm}$ (depth) by $16 \mathrm{~cm}$ (height). It can perform up to 16 reactions using standard $0.1 \mathrm{~mL}$ clear qPCR tubes with 10 to $100 \mu \mathrm{L}$ reaction volume each. The performance of this portable qPCR thermocycler was evaluated by comparing the LoD and amplification efficiency (E) of DIRECT-PCR assays.

\subsection{Statistical Analysis}

The limit of detection (LoD) was determined by plotting quantification cycle (Cq) against $\log _{10}$ copy number concentration. Correlation coefficient $\left(\mathrm{R}^{2}\right)$ was calculated by linear regression analysis. Amplification efficiency (E) was calculated from the slope of the log-linear curve using the given equation: $E=-1+10^{(-1 / \text { slope })}$. The slopes and intercepts of the linear regression lines were tested for statistical significance using Analysis of Covariance (ANCOVA) (GraphPad Prism 6). Repeatability and reproducibility of the RT-qPCR assay was determined by analysing the mean values and standard deviations of $\mathrm{C}_{\mathrm{q}}$ values.

\section{Results}

\subsection{Determination of LoD and Amplification Efficiency (E)}

Using synthetic RNA template of the SARS-CoV-2 N gene target, the limit of detection (LoD) of standard RT-qPCR was assessed to be 120 RNA copies per reaction with a quantification cycle $\left(C_{q}\right)$ mean value of $40.67 \pm 0.29$. However, no amplification was observed when RNA was spiked in sputum and nasal exudate using this standard mastermix. Using a PCR inhibitor resistant mastermix, the LoD of DIRECT-PCR was determined to be 120 RNA copies per reaction with a $C_{q}$ mean value of $38.48 \pm 0.57$ at the 7 th order of magnitude (Table 1 ). The lowest $C_{q}$ was observed at $17.37 \pm 0.04$, 
which corresponded to $1.2 \times 10^{8}$ RNA copies per reaction (Figure 1A). The DIRECT-PCR assay was completed in $72 \mathrm{~min}$ on the benchtop thermocycler. The control assay has amplification efficiency (E) of $84.94 \%$ with a correlation coefficient $\left(\mathrm{R}^{2}\right)$ of 0.9884 (Figure 1D). No amplification was observed for the non-template control (NTC) using water.

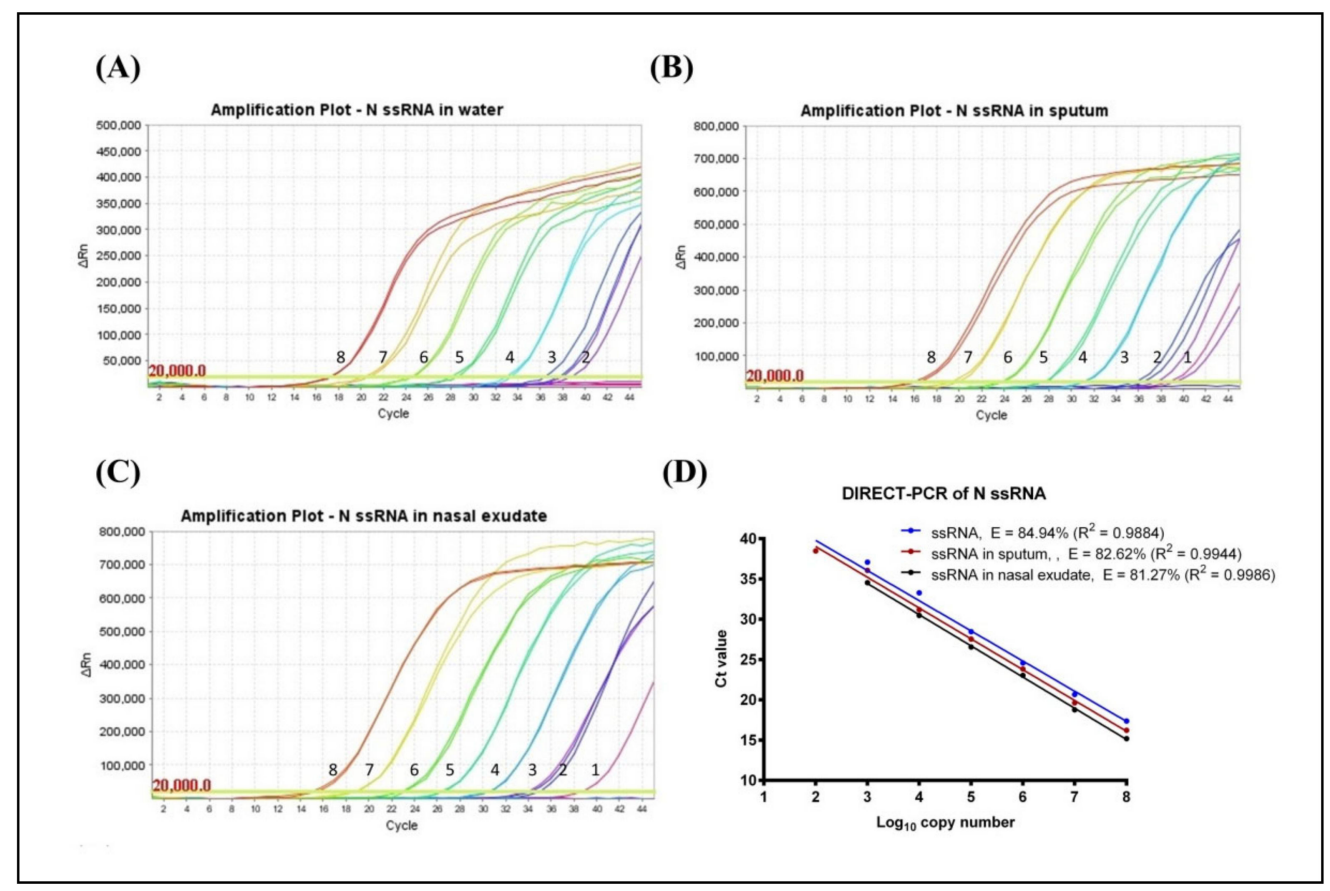

Figure 1. Amplification plot of SARS-CoV-2 N gene ssRNA control in (A) water, (B) spiked in sputum, and (C) spiked in nasal exudate conducted in the same thermocycler run. Numbers indicated the $\log _{10}$ copy number of the template present. No amplification was observed in the NTC. (D) Comparison of DIRECT-PCR assay amplification of SARS-CoV-2 N gene ssRNA control (blue line), $\mathrm{N}$ gene spiked in sputum (red line) and $\mathrm{N}$ gene spiked in nasal exudate (black line). Templates were ten-fold diluted in 8 orders of magnitude. Two microliters of template was used in $20 \mu \mathrm{L}$ of PCR mastermix on the benchtop thermocycler. The amplification efficiency $(\mathrm{E})$ was determined by plotting of mean $\mathrm{C}_{\mathrm{q}}$ values against $\log _{10}$ copy number calculated using theoretical molarity of templates.

Next, the DIRECT-PCR assay was evaluated using RNA spiked in sputum and nasal exudate matrices. The amplification of spiked RNA with PCR inhibition tolerance was observed with the concentration of sputum and nasal exudate at $4.25 \%(\mathrm{v} / \mathrm{v})$ in the PCR reaction. In RNA-spiked sputum samples, the sensitivity was greater than the control at 12 RNA copies per reaction with a $\mathrm{C}_{\mathrm{q}}$ of 38.79 (Table 1). The assay was reproducible within a relative mean standard deviation of 0.47 . The lowest $C_{q}$ was observed at $16.22 \pm 0.24$ which corresponded to $1.2 \times 10^{8}$ RNA copies per reaction (Figure $1 \mathrm{~B}$ ). When RNA was spiked in nasal exudate, we found the LoD of 12 RNA copies per reaction with a $C_{q}$ of 38.72 (Table 1). These LoDs were achieved in one out of two duplicates tested. The lowest $\mathrm{C}_{\mathrm{q}}$ in nasal exudate was observed at $15.18 \pm 0.36$ which corresponded to $1.2 \times 10^{8}$ RNA copies per reaction (Figure 1C). The PCR efficiency revealed lower amplification efficiency (E) when spiked into sputum $(82.62 \%)$ and nasal exudate $(81.27 \%)$ compared to control while the correlation coefficient $\left(\mathrm{R}^{2}\right)$ at 0.9944 and 0.9986 for sputum and nasal exudate, respectively. The linear regression lines had similar slopes $(p$-value $=0.6503)$ while the intercepts were significantly different ( $p$-value $<0.0001)$ (Figure 1D). 
Table 1. Limit of detection (LoD) in copies per PCR reaction volume and PCR efficiency of DIRECT-PCR for SARS-CoV-2 on benchtop and portable thermocyclers.

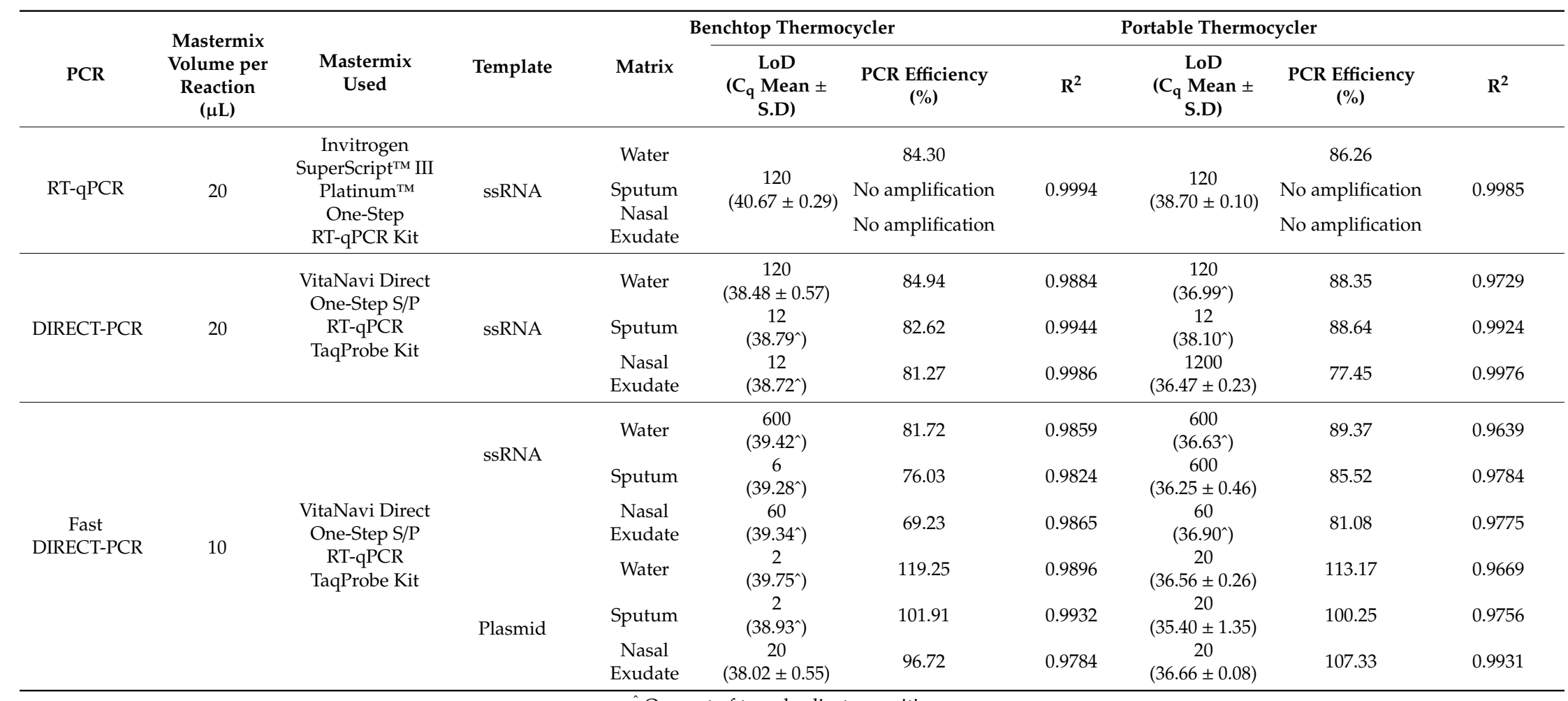

'One out of two duplicates positive. 


\subsection{Evaluation of Fast DIRECT-PCR Assay}

To reduce the duration and cost of the DIRECT-PCR assay, we modified the total reaction volume to $10 \mu \mathrm{L}$ and duration of cycling conditions with the addition of $1 \mu \mathrm{L}$ template. Amplification of RNA template using the fast DIRECT-PCR demonstrated detection at 600 RNA copies per reaction $\left(\mathrm{C}_{\mathrm{q}}\right.$ of $39.42)$ in contrast to 120 RNA copies per reaction $\left(C_{q}\right.$ of $\left.38.48 \pm 0.57\right)$ detected on the DIRECT-PCR assay. This optimized fast DIRECT-PCR was completed in $36 \mathrm{~min}$, as compared to $72 \mathrm{~min}$ for the DIRECT-PCR assay. The LoD was similar at $6\left(C_{q}\right.$ of 39.28) and 60 RNA copies per reaction $\left(C_{q}\right.$ of 39.34) when spiked into sputum and nasal exudate samples, respectively (Table 1). Using positive control plasmids encoding the $\mathrm{N}$ gene of SARS-CoV-2, the LoD was found to be 2 copies per reaction $\left(C_{q}\right.$ of 39.75) using the benchtop thermocycler. LoD of 2 and 20 copies per reaction was observed when the plasmids were spiked into sputum and nasal exudate samples with $C_{q}$ of 38.93 and $C_{q}$ mean of $38.02 \pm 0.55$, respectively, over four orders of magnitude (Figure 2). No amplification was observed for the negative controls using MERS-CoV and SARS-CoV plasmids. The human ribonuclease P (RP) primers were used as an internal control to amplify human RP RNA present in the crude samples, indicating that the DIRECT-PCR detected the presence of human RNA. Using crude sputum and nasal exudate directly, the mean $C_{q}$ values for human $R P$ was $26.12 \pm 0.24$ and $27.76 \pm 0.81$, respectively, on the benchtop thermocycler.

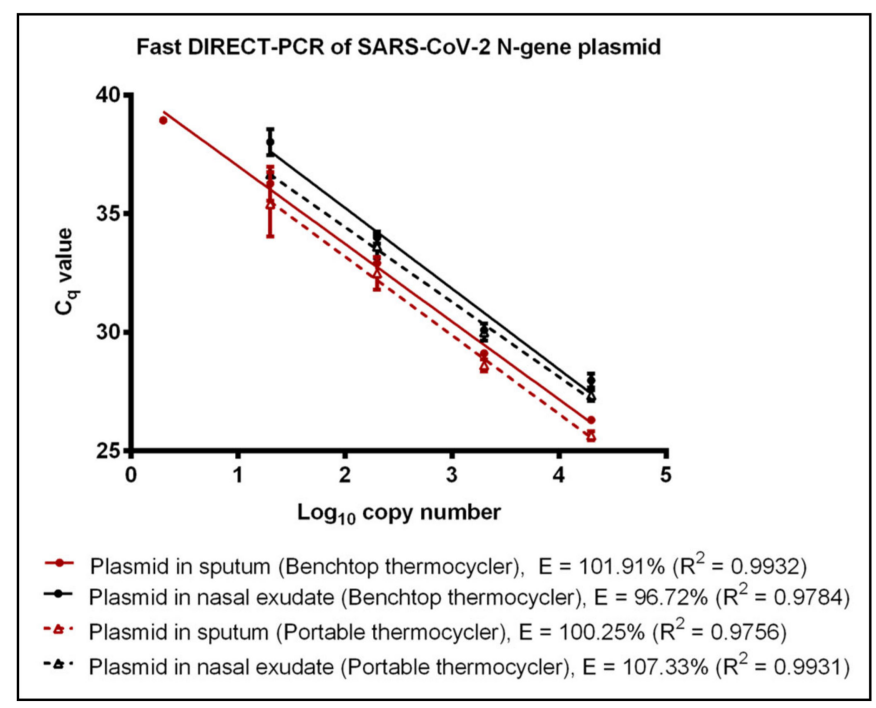

Figure 2. Fast DIRECT-PCR assay amplification efficiency of SARS-CoV-2 N gene plasmid spiked in sputum (red line) and $\mathrm{N}$ gene plasmid spiked in nasal exudate (black line) using the benchtop thermocycler (solid line) and the portable thermocycler (dotted line). Templates were ten-fold diluted in 6 orders of magnitude. One microliter of template was used in $10 \mu \mathrm{L}$ of PCR mastermix.

\subsection{Performance of Portable Thermocycler}

A commercially available portable qPCR thermocycler was validated by comparing to the benchtop thermocycler using the fast DIRECT-PCR assay of RNA and plasmid templates spiked in sputum and nasal exudate. The amplification efficiency of RNA control showed that there was no significant difference ( $p$-value $=0.4344$ ) between benchtop and the portable thermocycler. Both thermocyclers had similar LoD at 600 RNA copies per reaction (Table 1). When using RNA spike-in sputum, the portable thermocycler had LoD of 600 RNA copies per reaction $\left(C_{q}\right.$ of $\left.36.25 \pm 0.46\right)$ compared to six RNA copies per reaction when using the benchtop thermocycler (Table 1). On the other hand, both thermocyclers had the same LoD of 60 RNA copies per reaction when using RNA spike-in nasal exudate (Table 1). Using plasmid controls, there was no significant difference ( $p$-value $=0.7799$ ) in amplification efficiency between benchtop thermocycler and portable thermocycler (Figure 2). Next, 
using plasmids encoding the N gene of SARS-CoV-2 as control, the LoD was found to be 2 and 20 copies per reaction when using plasmid template and plasmid spike-in sputum for benchtop thermocycler and portable thermocycler, respectively. Both thermocyclers had similar sensitivity of 20 copies per reaction when using plasmid spike-in nasal exudate (Table 1). In terms of duration, the reaction took $49 \mathrm{~min}$ on the portable thermocycler and $36 \mathrm{~min}$ on benchtop thermocycler.

\section{Discussion}

Quantitative RT-PCR of SARS-CoV-2 RNA is currently the method of choice for the diagnosis of Covid-19. In our DIRECT-PCR method, we used inhibitor-resistant enzymes and reagents to eliminate the RNA extraction step. The use of synthetic RNA as template obviated the need to handle viral nucleic acids. With fast DIRECT-PCR protocol, we achieved further reduction in assay time by optimizing the thermocycling conditions. We also validated the analytical performance of DIRECT-PCR on spiked crude samples and demonstrated its use on a portable platform.

Current RT-qPCR for SARS-CoV-2 involves RNA purification as part of the pre-PCR sample preparation procedure and at least four to six hours are needed for time-to-results in most laboratories [16]. When the cycling conditions were optimized in our fast DIRECT-PCR with small reaction volumes $(10 \mu \mathrm{L})$, and shorter RT and annealing durations, we were able to amplify SARS-CoV-2 in less than an hour (Figure 3). Furthermore, there are cost savings on nucleic acid extraction kits, and the availability of reagents themselves may be limiting when laboratory capacity is ramped up and demand is increased globally. Moreover, DIRECT-PCR is a single-tube homogeneous reaction that reduces hands-on time and biosafety risk for laboratory personnel, as well as the likelihood for carryover contamination. One caveat, however, for fast DIRECT-PCR of samples with low viral load is that of sampling error, as only $1 \mu \mathrm{L}$ of sample is used. Nucleic acid extractions, on the other hand, serve to concentrate RNA from typical sample volumes of 150-300 $\mu \mathrm{L}$, although their yield can also be low and variable. Therefore, where samples are expected to have low counts near to the limit of detection, DIRECT-PCR with larger volume reactions $(25 \mu \mathrm{L})$ to include higher template volume may be necessary to reduce risk of false negatives.

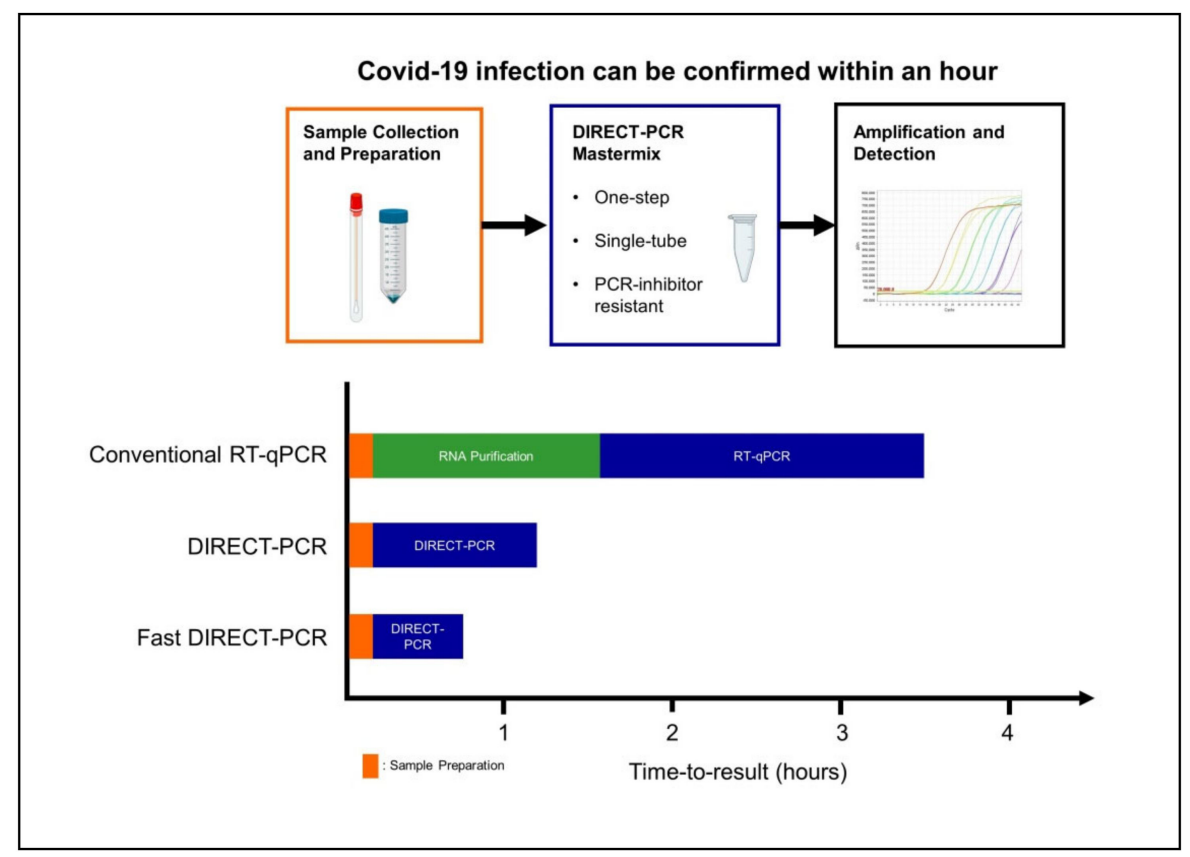

Figure 3. Workflow of fast DIRECT-PCR protocol for the direct detection of SARS-CoV-2. Covid-19 infection can be confirmed in less than an hour after sample collection and addition to mastermix for amplification and detection. 
Reduction in amplification efficiency is a common concern in DIRECT-PCR from crude samples (e.g., respiratory samples, blood, and serum). The presence of PCR inhibitors can decrease the sensitivity and accuracy of pathogen detection through interfering with polymerase activity, degradation of nucleic acids and efficient cell lysis [24]. A variety of methods have been developed to overcome such inhibition, including inhibitor tolerant polymerases, additives, and buffer modification. In our study, we used one commercially available formulation that tolerated PCR inhibition in sputum and nasal exudates as well as blood/serum/urine (data not shown), and it is not unlikely that other formulations could be used as well in our study. While amplification directly from sputum and nasal exudate reduced the efficiency of PCR compared to water controls, there was no net effect on the threshold of detection.

Nasopharyngeal swabs and sputum have been suggested to be effective clinical samples for diagnosis [28,29], and we have assessed direct PCR using these matrices. It should be feasible to extend this to other common samples used for Covid-19 testing, such as swabs of the throat and endotracheal tubes, and bronchoalveolar lavage fluid. Currently, our assay has successfully directly amplified from sputum and nasal exudate respiratory samples. If viral transport medium is used, it will need to be assessed for PCR inhibition. These mediums should ideally be in smaller volumes so that there is a less dilution effect on the sample concentration. Although we have focused our DIRECT-PCR protocols on commonly used primer-probe sets developed by the China CDC and US CDC that target the SARS-CoV-2 N gene as well as ORF1ab gene and the internal control RP, we expect direct PCR to be similarly useful for other viral primer targets and PCR amplicons developed for Covid-19 [8,9], as well as for multiplexed amplification of several targets in the same tube. Nevertheless, there may be other inhibitors of PCR that were not present in our samples that we tested, and clinical validation with a larger series is needed to exclude this possibility.

Quantitation of viral nucleic acid in samples by RT-qPCR has been used in studies to correlate viral load with severity, prognosis and transmissibility. The $\mathrm{C}_{\mathrm{q}}$ values in patients' samples can range from 19 to late cycles close to 40 during the course of infection. The nasal viral load has been shown to peak within days of symptom onset according to small study of throat and nasal swabs from 17 patients [30]. Using RNA as template, our DIRECT-PCR assay has a dynamic range of over 7 orders of magnitude with mean $\mathrm{C}_{\mathrm{q}}$ range from 17 to 38 , indicating it is reproducibly quantitative over a wide range, including very high viral titers. This method could be useful in future studies, such as to assess viral survivability, decontamination methods, and preventive intervention.

We have observed, even in spiked water samples, that amplification efficiencies and the $C_{q}$ values obtained at the limit of detection are dependent on factors such as the reagent mastermix, the model of thermocycler, the reaction volumes, and the cycling protocols used (Table 1). This variability would be even more significant in a clinical setting, with the added confounding factors, such as type of sample, sampling method, dilution in transport buffers, duration and conditions of storage, and the reagents and protocols for RNA extraction, that are difficult to standardize across healthcare settings and laboratories. While removing the RNA extraction step could help to reduce this variability in RNA yield and quality, variability in sample type and sampling procedure still renders the entire assay non-quantitative. Therefore, we caution overinterpretation of $\mathrm{C}_{\mathrm{q}}$ values, especially in the absence of in-house quality control and calibration data for each combination of protocol, reagents and thermocycler. These technical factors may also partly explain some of the false negatives and temporal variability in viral RNA shedding reported in various studies, that use fixed criteria $\mathrm{C}_{\mathrm{q}}<37$ for positive, $\mathrm{C}_{\mathrm{q}}$ between 37 to 40 as inconclusive for repeat testing and $\mathrm{C}_{\mathrm{q}}>40$ as negative. In fact, our data demonstrates that as viral RNA concentrations approach the threshold of detection, our assay LoD has $C_{q}$ mean value of $>37$ and may exceed 40 (Table 1). As negative controls in these probe-based assays remain consistently negative, it should be possible to report $C_{q}>37$ as positive. Therefore, to achieve better standardization of quantitative results, we propose that instead of reporting $C_{q}$, laboratories may report the equivalent viral copy number in per unit sample volume, derived from running serial dilutions of viral or RNA controls in-house. 
Our DIRECT-PCR assay has been demonstrated on a commercially available portable thermocycler that weighs less than $2 \mathrm{~kg}$, potentially allowing PCR to be performed outside molecular biology laboratories, in mobile laboratories, and in low resource settings. There are many real-time fieldable thermocyclers available that are smaller, portable, and less costly than benchtop ones, and for three of these we have evaluated perform similar to benchtop ones (data not shown). Although the optical detection modules and their fluorescence sensitivity vary between designs, the overall sensitivity of our assay was similar in both types of thermocyclers tested (Table 1). Thermocycling parameters could also be optimized for rapidity (Figure 3). As the need to transport samples to central laboratories could prolong the availability of test results to beyond $24 \mathrm{~h} \mathrm{[16],} \mathrm{use} \mathrm{of} \mathrm{portable} \mathrm{thermocyclers,} \mathrm{coupled}$ with appropriate training and quality control procedures, could allow the use of RT-qPCR nearer to the patients and in primary healthcare settings [12]. Such rapid point-of-care (POC) tests for use at community level were identified by a WHO expert group as a key research priority [31].

Though it is unlikely that DIRECT-PCR would completely replace conventional RNA extraction with RT-qPCR in large laboratories as a confirmatory diagnosis, the trade-off in reliability for portability, ease of use and cost-effectiveness could be useful for patient screening and public health surveillance and in settings with limited laboratory resources and facilities [4]. DIRECT-PCR for Covid-19 could address the specific requirements and challenges of delivering molecular genetic testing at the POC setting. POC diagnostics could play an important role in the detection, diagnosis and control of this pandemic [17], such as for more timely diagnosis in primary healthcare facilities, and to complement real-time fever surveillance and screening. Several technologies have been proposed and used to enable molecular testing at POC, including isothermal amplification methods that do not require such thermocyclers, like loop-mediated isothermal amplification (LAMP) [12]. However, given the widespread validation of existing SARS-CoV-2 PCR primer/probe sets, as well as the likely need to modify amplification primers and probes as the viral sequences evolve in the future, we argue that performing PCR using our DIRECT-PCR method is a more generic and adaptable approach. Indeed, while this manuscript was under review, other efforts to develop an extraction-free protocol to detect SARS-CoV-2 were reported [32-40].

\section{Conclusions}

Direct amplification of SARS-CoV-2 viral RNA from samples without RNA purification has been developed, reducing hands-on-time, time-to-results, and costs. Viral lysis, reverse transcription, amplification, and detection are achieved in a single-tube homogeneous reaction taking less than an hour, and they can be performed on a portable thermocycler. Analytical validation was performed with sputum and nasal exudate. The DIRECT-PCR assay has a high sensitivity of six RNA copies per reaction and is quantitative over a dynamic range of 7 orders of magnitude. This method may be useful during the current global Covid-19 pandemic in situations where resources are constrained or where timely results are needed.

Supplementary Materials: The following are available online at http://www.mdpi.com/2073-4425/11/6/664/s1, Supplementary Information S1.

Author Contributions: Conceptualization, S.K.W., S.P.S., and E.P.H.Y.; methodology, S.K.W., S.P.S., and E.P.H.Y.; investigation, S.K.W. and S.P.S.; formal analysis, S.K.W., S.P.S., and E.P.H.Y.; funding acquisition, E.P.H.Y.; supervision, E.P.H.Y.; visualization, S.K.W., S.P.S., and E.P.H.Y.; writing-original draft preparation, S.K.W. and S.P.S.; writing-review and editing, S.K.W., S.P.S., and E.P.H.Y. All authors have read and agreed to the published version of the manuscript.

Funding: This research is supported by the National Research Foundation, Prime Minister's Office, Singapore under its Competitive Research Programme (CRP13-2014-01, E.P.H.Y.) and Lee Kong Chian School of Medicine, Nanyang Technological University Singapore Start-Up Grant (E.P.H.Y.).

Conflicts of Interest: The authors declare no conflict of interest. The funders had no role in the design of the study; in the collection, analyses, or interpretation of data; in the writing of the manuscript; or in the decision to publish the results. 


\section{References}

1. Zhu, N.; Zhang, D.; Wang, W.; Li, X.; Yang, B.; Song, J.; Zhao, X.; Huang, B.; Shi, W.; Lu, R.; et al. A Novel Coronavirus from Patients with Pneumonia in China, 2019. New Engl. J. Med. 2020, 382, 727-733. [CrossRef] [PubMed]

2. WHO. WHO Director-General's Opening Remarks at the Media Briefing on COVID-19 - 11 March 2020. Available online: https://www.who.int/dg/speeches/detail/who-director-general-s-opening-remarks-at-themedia-briefing-on-covid-19---11-march-2020 (accessed on 12 March 2020).

3. WHO. COVID-19 Dashboard. Available online: https://covid19.who.int/ (accessed on 16 April 2020).

4. Beeching, N.J.; E Fletcher, T.; Beadsworth, M.B.J. Covid-19: Testing times. BMJ 2020, 369, m1403. [CrossRef] [PubMed]

5. Ng, Y.; Li, Z.; Chua, Y.X.; Chaw, W.L.; Zhao, Z.; Er, B.; Pung, R.; Chiew, C.J.; Lye, D.C.; Heng, D.; et al. Evaluation of the Effectiveness of Surveillance and Containment Measures for the First 100 Patients with COVID-19 in Singapore - January 2-February 29, 2020. MMWR. Morb. Mortal. Wkly. Rep. 2020, 69, 307-311. [CrossRef]

6. Wong, J.E.L.; Leo, Y.S.; Tan, C.C. COVID-19 in Singapore-Current Experience. JAMA 2020, $323,1243$. [CrossRef]

7. MOH. Updates on COVID-19 (Coronavirus Disease 2019) Local Situation. Available online: https://www. moh.gov.sg/covid-19 (accessed on 16 April 2020).

8. Zhang, Y.-Z. Novel 2019 Coronavirus Genome. Available online: http://virological.org/t/novel-2019coronavirus-genome/319 (accessed on 22 March 2020).

9. WHO. Coronavirus Disease (COVID-19) Technical Guidance: Laboratory Testing for 2019-nCoV in Humans. Available online: https://www.who.int/emergencies/diseases/novel-coronavirus-2019/technical-guidance/ laboratory-guidance (accessed on 26 March 2020).

10. NUS. SSHSPH COVID-19 Science Report; Saw Swee Hock School of Public Health, National University of Singapore: Singapore, 2020.

11. WHO. Laboratory testing for 2019 Novel Coronavirus (2019-nCoV) in Suspected Human Cases; WHO/COVID-19/Laboratory/2020.5; World Health Organization: 2020. Available online: https:/www.who. int/publications/i/item/10665-331501 (accessed on 20 April 2020).

12. Nguyen, T.; Bang, D.D.; Wolff, A. 2019 Novel Coronavirus Disease (COVID-19): Paving the Road for Rapid Detection and Point-of-Care Diagnostics. Micromachines 2020, 11, 306. [CrossRef] [PubMed]

13. Wei, W.E.; Li, Z.; Chiew, C.J.; Yong, S.E.; Toh, M.P.; Lee, V.J. Presymptomatic Transmission of SARS-CoV-2 Singapore, January 23-March 16, 2020. MMWR. Morb. Mortal. Wkly. Rep. 2020, 69, 411-415. [CrossRef]

14. He, X.; Lau, E.H.; Wu, P.; Deng, X.; Wang, J.; Hao, X.; Lau, Y.C.; Wong, J.Y.; Guan, Y.; Tan, X.; et al. Temporal dynamics in viral shedding and transmissibility of COVID-19. Nat. Med. 2020, 26, 672-675. [CrossRef]

15. Gudbjartsson, D.F.; Helgason, A.; Jonsson, H.; Magnusson, O.T.; Melsted, P.; Norddahl, G.L.; Saemundsdottir, J.; Sigurdsson, A.; Sulem, P.; Agustsdottir, A.B.; et al. Spread of SARS-CoV-2 in the Icelandic Population. New Engl. J. Med. 2020, 382, 2302-2315. [CrossRef]

16. Sheridan, C. Fast, portable tests come online to curb coronavirus pandemic. Nat. Biotechnol. 2020, 38, 515-518. [CrossRef]

17. Patel, R.; Babady, N.E.; Theel, E.S.; Storch, G.A.; Pinsky, B.A.; George, K.S.; Smith, T.C.; Bertuzzi, S. Report from the American Society for Microbiology COVID-19 International Summit, 23 March 2020: Value of Diagnostic Testing for SARS-CoV-2/COVID-19. mBio. 2020, 11. [CrossRef]

18. Sivalingam, S.P.; Ayi, T.C.; Mustaffa, S.B.; Loo, S.; Tan, B.H.; Yap, E.P.H. Direct RT-PCR detection of Dengue 1-4 virus from crude samples for rapid point-of-care diagnosis. In Proceedings of the SingHealth Duke-NUS Scientific Congress, Singapore, 23-24 September 2016.

19. Mehta, N.; Perrais, B.; Martin, K.; Kumar, A.; Hobman, T.C.; Cabalfin-Chua, M.N.; Donaldo, M.E.; Painaga, M.S.S.; Gaite, J.Y.; Tran, V.; et al. A Direct from Blood/Plasma Reverse Transcription-Polymerase Chain Reaction for Dengue Virus Detection in Point-of-Care Settings. Am. J. Trop. Med. Hyg. 2019, 100, 1534-1540. [CrossRef]

20. Pastorino, B.; Bessaud, M.; Grandadam, M.; Murri, S.; Tolou, H.J.; Peyrefitte, C.N. Development of a TaqMan®RT-PCR assay without RNA extraction step for the detection and quantification of African Chikungunya viruses. J. Virol. Methods 2005, 124, 65-71. [CrossRef] [PubMed] 
21. Nishimura, N.; Nakayama, H.; Yoshizumi, S.; Miyoshi, M.; Tonoike, H.; Shirasaki, Y.; Kojima, K.; Ishida, S. Detection of noroviruses in fecal specimens by direct RT-PCR without RNA purification. J. Virol. Methods 2010, 163, 282-286. [CrossRef] [PubMed]

22. Bachofen, C.; Willoughby, K.; Zadoks, R.; Burr, P.; Mellor, D.; Russell, G.C. Direct RT-PCR from serum enables fast and cost-effective phylogenetic analysis of bovine viral diarrhoea virus. J. Virol. Methods 2013, 190, 1-3. [CrossRef] [PubMed]

23. Li, L.; He, J.-A.; Wang, W.; Xia, Y.; Song, L.; Chen, Z.-H.; Zuo, H.-Z.; Tan, X.-P.; Ho, A.H.-P.; Kong, S.-K.; et al. Development of a direct reverse-transcription quantitative PCR (dirRT-qPCR) assay for clinical Zika diagnosis. Int. J. Infect. Dis. 2019, 85, 167-174. [CrossRef]

24. Hall, A.T.; Zovanyi, A.M.; Christensen, D.R.; Koehler, J.W.; Minogue, T.D. Evaluation of Inhibitor-Resistant Real-Time PCR Methods for Diagnostics in Clinical and Environmental Samples. PLoS ONE 2013, 8, e73845. [CrossRef]

25. Wang, D.; Hu, B.; Hu, C.; Zhu, F.; Liu, X.; Zhang, J.; Wang, B.; Xiang, H.; Cheng, Z.; Xiong, Y.; et al. Clinical Characteristics of 138 Hospitalized Patients With 2019 Novel Coronavirus-Infected Pneumonia in Wuhan, China. JAMA 2020, 323, 1061. [CrossRef]

26. CDC, C. Specific Primers and Probes for Detection 2019 Novel Coronavirus. Available online: http: //ivdc.chinacdc.cn/kyjz/202001/t20200121_211337.html (accessed on 1 February 2020).

27. CDC. Research Use Only 2019-Novel Coronavirus (2019-nCoV) Real-Time RT-PCR Primer and Probe Information. Available online: https://www.cdc.gov/coronavirus/2019-ncov/lab/rt-pcr-panel-primer-probes. html (accessed on 2 March 2020).

28. Yang, Y.; Yang, M.; Shen, C.; Wang, F.; Jing, Y.; Li, J.-X.; Zhang, M.; Wang, Z.; Xing, L.; Wei, J.; et al. Evaluating the accuracy of different respiratory specimens in the laboratory diagnosis and monitoring the viral shedding of 2019-nCoV infections 2020. MedRxiv 2020.

29. Pan, Y.; Zhang, D.; Yang, P.; Poon, L.L.; Wang, Q. Viral load of SARS-CoV-2 in clinical samples. Lancet Infect. Dis. 2020, 20, 411-412. [CrossRef]

30. Zou, L.; Ruan, F.; Huang, M.; Liang, L.; Huang, H.; Hong, Z.; Yu, J.; Kang, M.; Song, Y.; Xia, J.; et al. SARS-CoV-2 Viral Load in Upper Respiratory Specimens of Infected Patients. New Engl. J. Med. 2020, 382, 1177-1179. [CrossRef]

31. WHO. COVID 19 Public Health Emergency of International Concern (PHEIC) - Global Research and Innovation Forum: Towards a Research Roadmap. Available online: https://www.who.int/blueprint/prioritydiseases/key-action/Global_Research_Forum_FINAL_VERSION_for_web_14_feb_2020.pdf?ua=1 (accessed on 14 April 2020).

32. Bruce, E.A.; Huang, M.-L.; Perchetti, G.A.; Tighe, S.W.; Laaguiby, P.; Hoffman, J.J.; Gerrard, D.L.; Nalla, A.K.; Wei, Y.; Greninger, A.L.; et al. DIRECT RT-qPCR DETECTION OF SARS-CoV-2 RNA FROM PATIENT NASOPHARYNGEAL SWABS WITHOUT AN RNA EXTRACTION STEP 2020. BioRxiv 2020.

33. Sentmanat, M.; Kouranova, E.; Cui, X. One-step RNA extraction for RT-qPCR detection of 2019-nCoV 2020. BioRxiv 2020.

34. Arumugam, A.; Wong, S.S. The Potential Use of Unprocessed Sample for RT-qPCR Detection of COVID-19 without an RNA Extraction Step 2020. BioRxiv 2020.

35. Grant, P.R.; Turner, M.; Shin, G.Y.; Nastouli, E.; Levett, L. Extraction-free COVID-19 (SARS-CoV-2) diagnosis by RT-PCR to increase capacity for national testing programmes during a pandemic. In bioRxiv 2020; Cold Spring Harbor Laboratory: Cold Spring Harbor, NY, USA, 2020.

36. Merindol, N.; Pépin, G.; Marchand, C.; Rheault, M.; Peterson, C.; Poirier, A.; Germain, H.; Danylo, A. Optimization of SARS-CoV-2 detection by RT-QPCR without RNA extraction 2020. bioRxiv 2020.

37. Smyrlaki, I.; Ekman, M.; Lentini, A.; Vondracek, M.; Papanicoloau, N.; Aarum, J.; Safari, H.; Muradrasoli, S.; Albert, J.; Högberg, B.; et al. Massive and rapid COVID-19 testing is feasible by extraction-free SARS-CoV-2 RT-qPCR 2020. medRxiv 2020.

38. Brown, J.R.; Atkinson, L.; Shah, D.; Harris, K. Validation of an extraction-free RT-PCR protocol for detection of SARS-CoV2 RNA 2020. medRxiv 2020. 
39. Hasan, M.R.; Mirza, F.; Al-Hail, H.; Sundararaju, S.; Xaba, T.; Iqbal, M.; Alhussain, H.; Yassine, H.M.; Lopez, A.P.; Tang, P. Detection of SARS-CoV-2 RNA by direct RT-qPCR on nasopharyngeal specimens without extraction of viral RNA 2020. medRxiv 2020.

40. Fomsgaard, A.S.; Rosenstierne, M.W. An alternative workflow for molecular detection of SARS-CoV-2 escape from the NA extraction kit-shortage, Copenhagen, Denmark, March 2020. Eurosurveillance 2020, 25, 2000398. [CrossRef]

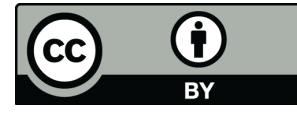

(C) 2020 by the authors. Licensee MDPI, Basel, Switzerland. This article is an open access article distributed under the terms and conditions of the Creative Commons Attribution (CC BY) license (http://creativecommons.org/licenses/by/4.0/). 